\title{
Perancangan Sistem Informasi Rekap Data Pasien Klinik Universitas Merdeka Madiun
}

\author{
Dwi Nor Amadi ${ }^{1}$, Hendra Budi Prasetyo ${ }^{2}$ \\ ${ }^{I}$ Fakultas Teknik, Universitas Merdeka Madiun, Jl. Serayu No. 79, Madiun, 63133 \\ E-mail: dwinor@unmer-madiun.ac.id \\ ${ }^{2}$ Fakultas Teknik, Universitas Merdeka Madiun, Jl. Serayu No. 79, Madiun, 63133 \\ E-mail: hendra@unmer-madiun.ac.id
}

\begin{abstract}
Administration At the "Merdeka madiun" university clinic currently not well ordered and have not utilised IT technology, for it needs to build an information system that contains track records of patients who have done the examination or treatment at an independent "Merdeka madiun" university clinic. For that, we need to think about how to make information system of patient data recap at "Merdeka madiun" university clinic. So that traceable history of patient health and Built a Patient Data Recap at the "Merdeka madiun" university with an android and web-based opensource platform.
\end{abstract}

Keywords - : Information system; Clinic.

\section{PENDAHULUAN}

Kebutuhan Internet untuk menunjang perkembangan teknologi informasi saat ini semakin meningkat, saat ini manusia tidak bisa lepas dari kebutuhan akan koneksi internet, bahkan saat ini pemanfaatan internet merupakan salah satu kebutuhan pokok yang tidak bisa di tinggal kan untuk menunjang perkembangan teknologi informasi. Disamping kebutuhan akan perkembangan perangkat keras seperti gadget dan lain sebagainya.

Administrasi Di klinik universitas merdeka madiun saat ini belum tertata dengan baik dan belum memanfaatkan teknologi IT, untuk itu perlu dibuat sebuah sistem informasi yang berisi rekam jejak data pasien yang pernah melakukan pemeriksaan atau berobat di klinik universitas merdeka madiun. Diharapkan dengan adanya sistem informasi rekap data pasien di klinik universitas merdeka madiun maka histori data pasien

\section{TINJAUAN PUSTAKA}

\section{A. Sistem}

Sistem berasal dari bahasa Latin (systema) dan bahasa Yunani (sustema) adalah suatu kesatuan yang terdiri komponen atau elemen yang dihubungkan bersama untuk memudahkan aliran informasi, materi atau energi untuk mencapai suatu tujuan. Istilah ini sering dipergunakan untuk menggambarkan suatu set entitas yang berinteraksi, di mana suatu model matematika seringkali bisa dibuat. Sistem juga merupakan kesatuan bagian-bagian yang saling berhubungan yang berada dalam suatu wilayah serta memiliki item-item penggerak.

\section{B. Open Source}

Perangkat lunak Open Source adalah jenis perangkat lunak yang kode sumber-nya terbuka untuk dipelajari, diubah, ditingkatkan dan disebarluaskan. Karena sifat ini, umumnya pengembangannya dilakukan oleh satu paguyuban terbuka yang bertujuan mengembangkan perangkat lunak bersangkutan. Anggota-anggota paguyuban itu seringkali sukarela tapi bisa juga pegawai suatu perusahaan yang dibayar untuk membantu pengembangan perangkat lunak itu. Produk perangkat lunak yang dihasilkan ini biasanya bersifat bebas dengan tetap menganut kaidah dan etika tertentu.

\section{Situs Web}

Situs web (bahasa Inggris: website) adalah suatu halaman web yang saling berhubungan yang umumnya berada pada server yang sama berisikan kumpulan informasi yang disediakan secara perorangan, kelompok, atau organisasi. Sebuah situs web biasanya ditempatkan setidaknya pada sebuah server web yang dapat diakses melalui jaringan seperti

Internet, ataupun jaringan wilayah lokal (LAN) melalui alamat Internet yang dikenali sebagai URL. Gabungan atas semua situs yang dapat diakses publik di Internet disebut pula sebagai World Wide Web atau lebih dikenal dengan singkatan WWW. halaman beranda situs Internet umumnya dapat diakses publik secara bebas, pada praktiknya tidak semua situs memberikan kebebasan bagi publik untuk mengaksesnya, 


\section{XAMPP}

XAMPP adalah perangkat lunak bebas, yang mendukung banyak sistem operasi, merupakan kompilasi dari beberapa program. Fungsinya adalah sebagai server yang berdiri sendiri (localhost), yang terdiri atas program Apache HTTP Server, MySQL database, dan penerjemah bahasa yang ditulis dengan bahasa pemrograman PHP dan Perl. Nama XAMPP merupakan singkatan dari X (empat sistem operasi apapun), Apache, MySQL, PHP dan Perl. Program ini tersedia dalam GNU General Public License dan bebas, merupakan web server yang mudah digunakan yang dapat melayani tampilan halaman web yang dinamis. Untuk mendapatkanya dapat mendownload langsung dari web resminya.

\section{III.ANALISIS DAN PERANCANGAN}

\section{A. Alur Sistem}

\section{Flowchart Admin}

Proses diawali dari login kedalam sistem, kemudian jika berhasil login berhasil maka admin masuk kedalam sistem ditunjukan dengan tampilan menu utama, admin dapat memilih menu pasien dan kemudian melakukan pengolahan data pasien, berupa insert, edit, dan delete. Pada menu cekup admin dapat melakukan input data cekup dan dapat melihat daftar riwayat cekup pasien. Pada menu informasi admin dapat melakukan pengolahan data informasi kesehatan berupa insert data, edit data, dan hapus data. pada menu konsultasi admin dapat melakukan interaksi dengan pasien yang melakukan konsultasi berupa chating menggunakan sistem. Kemudian admin dapat keluar dari sistem dengan melakukan logout.

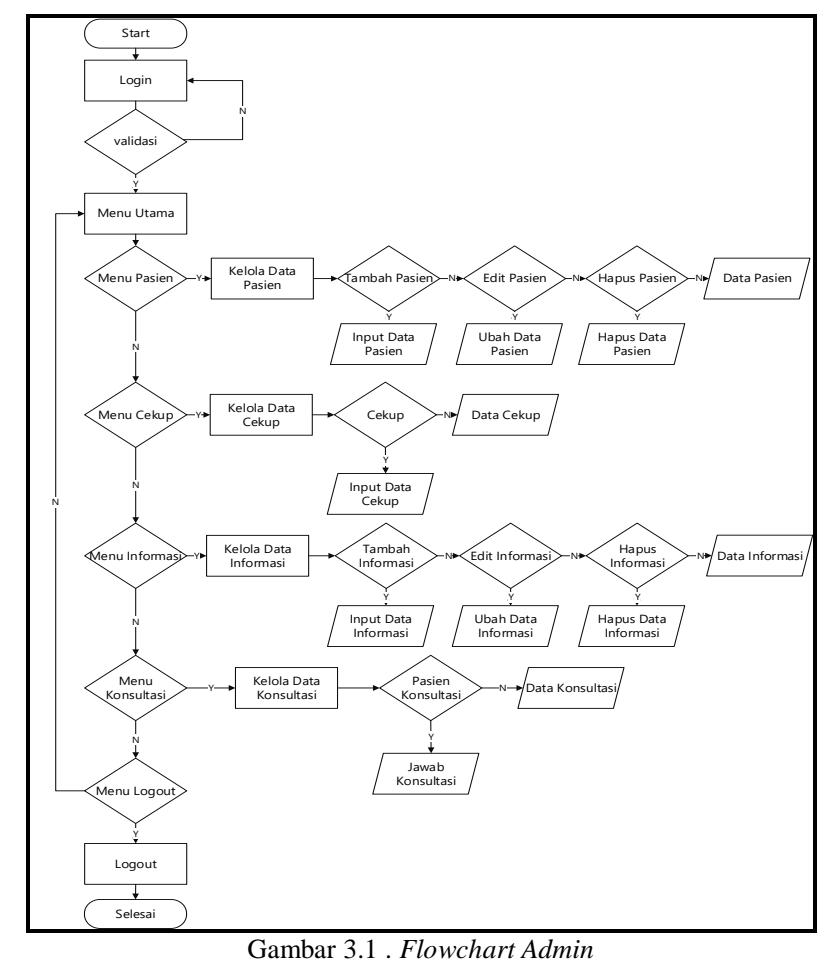

\section{Alur Sistem Flowchart Pasien}

Proses diawali dari login kedalam sistem, kemudian jika berhasil login berhasil maka admin masuk kedalam sistem ditunjukan dengan tampilan menu utama, pasien dapat melihat rekap cekup yang pernah dilakukannya. Pada menu konsultasi pasien dapat melakukan konsultasi dengan admin/perawat menggunakan sistem. Pada menu informasi pengguna dapat melihat daftar informasi seputar kesehatam kemudian dapat melihat detail dari informasi kesehatan tersebut. Pada menu profil pasien dapat melihat biodata dan dapat merubah data biodata tersebut. 


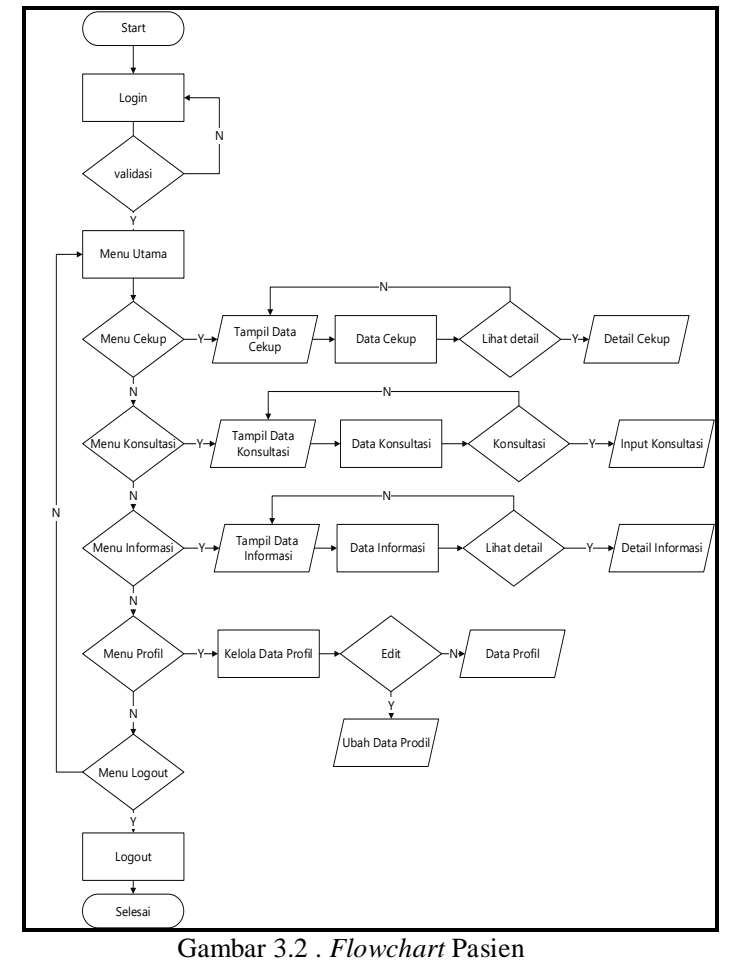

\section{B. Perancangan Database}

Tabel User

Nama tabel : users

Tabel user digunakan untuk menyimpan data user atau pasien data tabel ini dapat dikelola oleh admin.

\begin{tabular}{|l|l|l|l|}
\hline Nama Field & $\begin{array}{c}\text { Tipe } \\
\text { Data }\end{array}$ & Panjang & Keterangan \\
\hline id_user & varchar & 10 & $\begin{array}{l}\text { primary key, } \\
\text { foreign key }\end{array}$ \\
\hline password & varchar & 255 & \\
\hline email & varchar & 50 & \\
\hline kategori & enum & & \\
\hline status & enum & & \\
\hline _log_create & datetime & & \\
\hline _log_update & datetime & & \\
\hline _log_login & datetime & & \\
\hline _log_delete & enum & & \\
\hline
\end{tabular}

Tabel 3.1 Tabel User

Tabel Biodata User

Nama tabel : users_bio

Tabel biodata user berfungsi untuk menyimpan data biodata user yang berrelasi dengan tabel users dengan foreign key id_user 
PILAR TEKNOLOGI : Jurnal IImiah IImu-IImu Teknik

Website : http://pilar.unmermadiun.ac.id/index.php/pilarteknologi

\begin{tabular}{|l|l|l|l|}
\hline \multicolumn{1}{|c|}{ Nama Field } & Tipe Data & Panjang & Keterangan \\
\hline id_user & varchar & 10 & $\begin{array}{l}\text { primary key, } \\
\text { foreign key }\end{array}$ \\
\hline nama_lengkap & text & 255 & \\
\hline jenis_kelamin & enum & 50 & \\
\hline tempat_lahir & varchar & 20 & \\
\hline tanggal_lahir & date & & \\
\hline alamat & text & & \\
\hline agama & varchar & 10 & \\
\hline tlp & varchar & 14 & \\
\hline Foto & varchar & 25 & \\
\hline golongan_darah & varchar & 2 & \\
\hline tinggi_badan & int & & \\
\hline berat_badan & int & & \\
\hline
\end{tabular}

Tabel 3.2 Biodata Biodata User

Tabel Cekup

Nama tabel

: cekup

Tabel ini digunakan untuk menyimpan data cekup pasien yang dapat dikelola oleh admin dan dapat dilihat oleh pasien.

\begin{tabular}{|l|l|l|l|}
\hline \multicolumn{1}{|c|}{ Nama Field } & Tipe Data & Panjang & Keterangan \\
\hline id_cek & int & $\begin{array}{l}\text { primary } \\
\text { key }\end{array}$ \\
\hline id_user & varchar & 10 & $\begin{array}{l}\text { Foreign } \\
\text { Key }\end{array}$ \\
\hline tanggal & datetime & & \\
\hline subject & text & & \\
\hline object & text & & \\
\hline tekanan_datah & varchar & 30 & \\
\hline nadi & int & & \\
\hline respirator_rate & int & & \\
\hline suhu & int & & \\
\hline gd_acak & varchar & 10 & \\
\hline gb_puasa & varchar & 10 & \\
\hline gd_2jpp & varchar & 10 & \\
\hline diagnosa & varchar & 255 & \\
\hline tindakan_terapi & double & & \\
\hline berat_badan & double & & \\
\hline _user_input & varchar & 10 & \\
\hline _log_create & datetime & & \\
\hline
\end{tabular}

Tabel 3.3 Tabel Cekup 
Tabel Informasi

Nama tabel

$$
\text { : informasi }
$$

Tabel ini berfungsi untuk menyimpan informasi seputar kesehatan, tabel ini berrelasi dengan tabel admin sebagai user input yang mengelola data informasi.

\begin{tabular}{|l|l|l|l|}
\hline \multicolumn{1}{|c|}{ Nama Field } & $\begin{array}{c}\text { Tipe } \\
\text { Data }\end{array}$ & Panjang & Keterangan \\
\hline id & int & & primary key \\
\hline judul & varchar & 100 & \\
\hline content & text & & \\
\hline image & image & 50 & \\
\hline _user_input & varchar & 10 & Foreign Key \\
\hline _date_create & datetime & & \\
\hline _log_delete & enum & & \\
\hline
\end{tabular}

Tabel 3.4 Tabel Informasi

Tabel Konsultasi

Nama tabel

: konsultasi

Tabel konsultasi berfungsi untuk menyimpan data konsultasi pengguna/pasien dengan admin/perawat, tabel ini berrelasi dengan tabel user sebagai pengirim, dan admin sebagai tujuan.

\begin{tabular}{|l|l|l|l|}
\hline Nama Field & Tipe Data & Panjang & Keterangan \\
\hline id_chat & int & & primary key \\
\hline From & varchar & 10 & Foreign Key \\
\hline To & varchar & 10 & Foreign Key \\
\hline Content & text & & \\
\hline Time & time & 10 & \\
\hline Date & date & & \\
\hline read & enum & & \\
\hline time_read & datetime & & \\
\hline _log_delete & enum & & \\
\hline
\end{tabular}

Tabel 3.5 Tabel Konsultasi

Tabel admin

Nama tabel : admin

Tabel admin berfungsi menyimpan data admin atau perawat, yang berrelasi dengan tabel konsultasi, informasi, dan cekup.

\begin{tabular}{|l|l|l|l|}
\hline Nama Field & \multicolumn{1}{|c|}{ Tipe Data } & Panjang & Keterangan \\
\hline Id & int & & $\begin{array}{l}\text { primary key, foreign } \\
\text { key }\end{array}$ \\
\hline Fullname & varchar & 50 & \\
\hline Usermane & varchar & 10 & \\
\hline Password & Varchar & 255 & \\
\hline
\end{tabular}

Tabel 3.5 tabel admin 


\section{ERD (Entity Relationship Diagram)}

Berikut ini adalah ERD sistem:

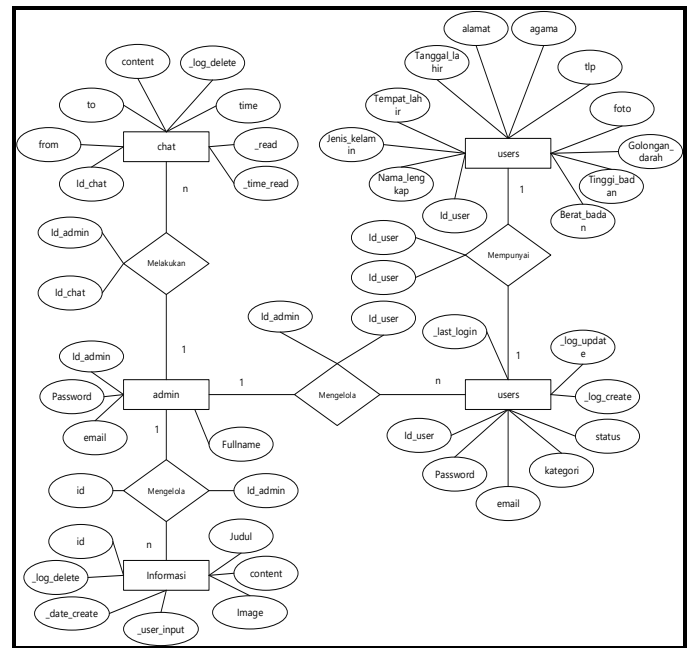

Gambar 3.3 ERD sistem.

\section{Relasi Database}

Berikut ini adalah relasi tabel sistem :

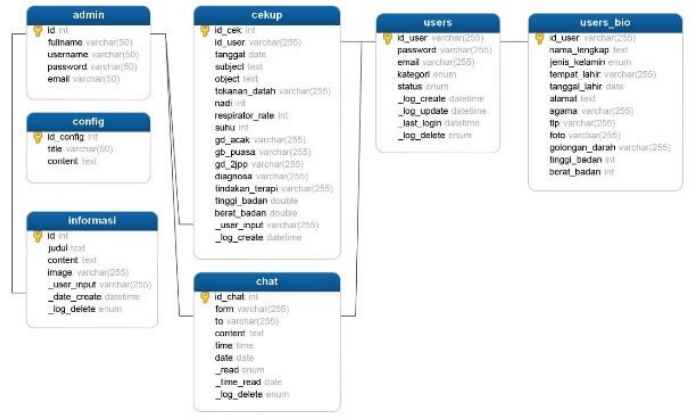

Gambar 3.4 Relasi tabel.

\section{Struktur Antar Muka Sistem}

Berikut ini adalah rancangan struktur antar muka sistem untuk admin (berbasis web)

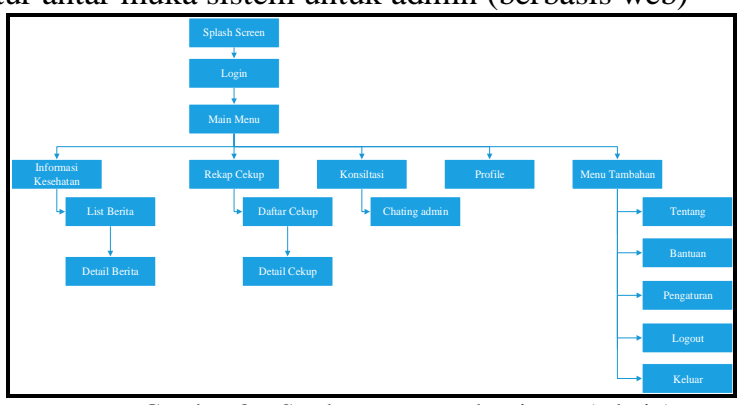

Gambar 3.6 Struktur antar muka sistem (admin) 
Untuk perancangan struktur antas muka sistem pengguna/pasien digambarkan sebagai berikut:

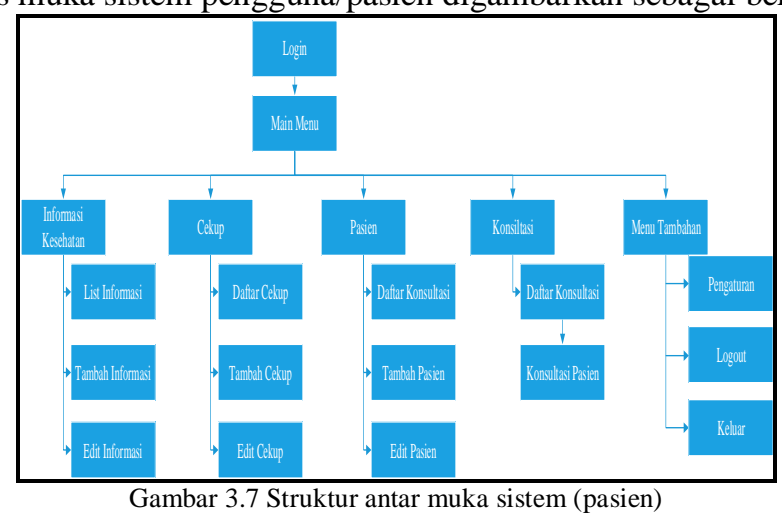

\section{Perancangan Interface Program (Android)}

Berikut ini adalah perancangan interface program untuk pengguna/user berbasis android :

a) Splash Screen

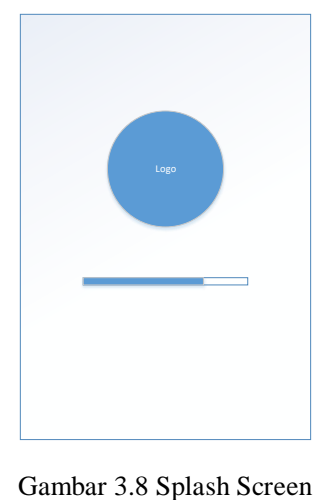

Splash screen adalah tampilan awal ketika pengguna/pasien membuka aplikasi, tampilan ini akan otomatis keluar setelah beberapa detik.

b) Login

Setelah splash screen tertutup makan tampilan berganti dengan tampilan login, user dapat memaukan username dan password kemudian dapat masuk kedalam sistem.

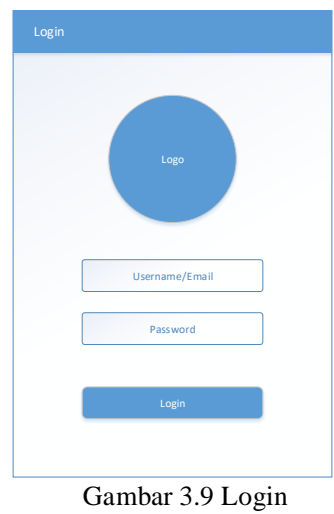


c) Menu Utama

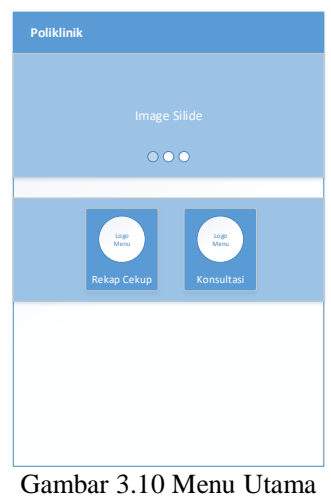

Setelah pasien berhasil melakukan login maka pasien dapat melihat menu utama, terdapat menu rekap cekup dan menu konsultasi, juga terdapat list informasi kesehatan.

d) Menu Navigasi

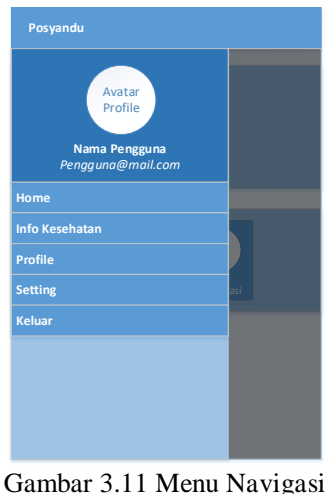

Pada menu navigasi pasien/pengguna dapat memilih beberapa menu, diantaranya home sebagai menu utama, info kesehatan untuk melihat informasi kesehatan, profile untuk melihat profil pengguna, setting dan keluar. Informasi Kesehatan

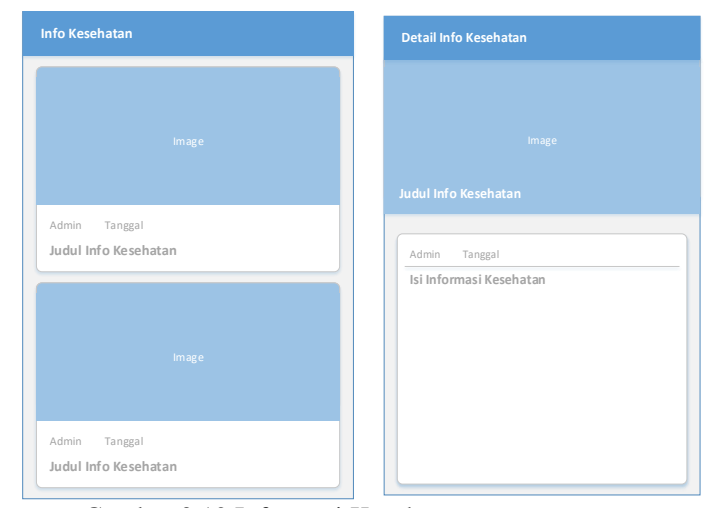

Gambar 3.12 Informasi Kesehatan

Pada gambar 3.12 dapat dilihat bagian kiri adalah list dari informasi kesehatan dan bagian kanan adalah detail dari informasi kesehatan. 
e) Rekap Cekup

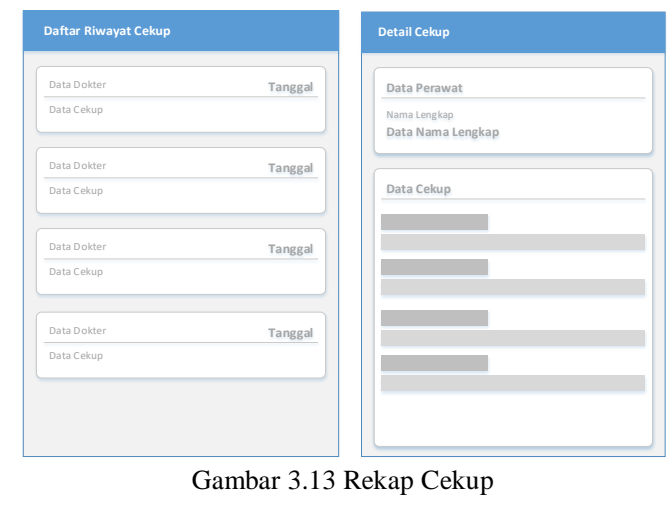

Pada gambar 3.13 dapat dilihat bagian kiri adalah list dari cekup yang telah dilakukan oleh pasien / pengguna dan bagian kanan adalah detail dari informasi cekup.

f) Konsultasi

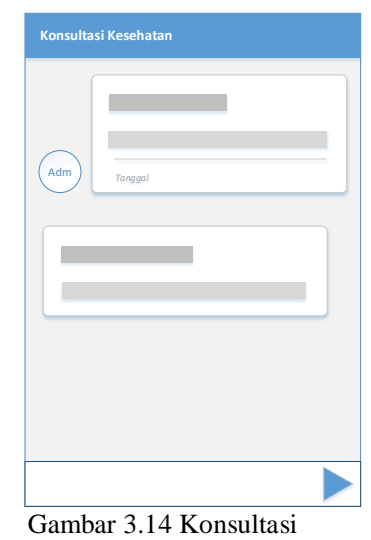

Gambar 3.14 adalah perancangan interface menu Konsultasi, pada tampilan ini pasien/pengguna dapat melakukan konsultasi dengan admin/perawat.

\section{IV.KESIMPULAN DAN SARAN}

\section{A. Kesimpulan}

Pada penelitan kali ini telah berhasil dibuat sebuah perancangan sistem dan perancangan antar muka untuk rekap data pasien di klinik. Perancangan meliputi perancangan database dan perancangan antar muka dan perancangan sistem informasi rekap data pasien.

\section{B. Saran}

Untuk kedepan nya penelitian ini masih dalam tahap perancangan yang bisa dilanjutkan kedalam tahap pembuatan aplikasi sehingga dapat diaplikasikan di klinik yang membutuhkan. 


\section{DAFTAR PUSTAKA}

Jogiyanto, H. 2003. Analisis dan Desain Sistem Informasi Edisi kedua. CetakanPertama. Yogyakarta: Penerbit Andi Offset Yogyakarta. Park. 1979. Pengertian Sistem. http://id.wikipedia.org. Diakses pada 25 November2014

Chaudhury, Abijit \& Jean-Pierre Kuilboer (2002), e-Business and e-Commerce Infrastructure, McGraw-Hill, ISBN 0-07-247875-6

Seybold, Pat (2001), Customers.com Crown Business Books (Random House), ISBN 0-609-60772-3

St. Laurent, Andrew M. (2008). Understanding Open Source and Free Software Licensing. O'Reilly Media. p. 4. ISBN 9780596553951.

"Definisi situs web" (dalam Inggris). The Free Dictionary by Farlex. Diakses tanggal 30 Juli 2017. 